\title{
Assessing Resilience to Climate Change in US Cities
}

\author{
Casilda Saavedra, ${ }^{1}$ William W. Budd, ${ }^{2}$ and Nicholas P. Lovrich ${ }^{3}$ \\ ${ }^{1}$ College of Civil Engineering, Technological University of Panama, P.O. Box 0819-07289, El Dorado, Panama City, Panama \\ ${ }^{2}$ Division of Governmental Studies and Services, Department of Political Science, Washington State University, \\ Pullman, WA 99163, USA \\ ${ }^{3}$ Department of Political Science, Washington State University, Pullman, WA 99163, USA
}

Correspondence should be addressed to Casilda Saavedra, casilda.saavedra@utp.ac.pa

Received 1 December 2011; Accepted 9 March 2012

Academic Editor: Karen F. Parker

Copyright (C) 2012 Casilda Saavedra et al. This is an open access article distributed under the Creative Commons Attribution License, which permits unrestricted use, distribution, and reproduction in any medium, provided the original work is properly cited.

\begin{abstract}
In the face of uncertainties associated with climate change, building adaptive capacity and resilience at the community level emerges as an essential and timely element of local planning. However, key social factors that facilitate the effective building and maintenance of urban resilience are poorly understood. Two groups of US cities differing markedly in their commitment to climate change are contrasted with respect to their planning approaches and actions related to mitigation and adaptation strategies, and also in relation to social features that are believed to enhance adaptive capacity and resilience to climate change. The first group manifests a strong commitment to climate change mitigation and adaptation, and the second group has demonstrated little or no such commitment. These cities are compared with respect to several noteworthy social features, including level of social capital, degree of unconventional thought, and level of cultural diversity. These characteristics are postulated to contribute to the adaptive capacity of communities for dealing with the impacts of climate change. The aim is to determine to what extent there is a relationship between social/cultural structures and urban commitment and planning for climate change that could discriminate between climate change resilient and nonresilient urban areas.
\end{abstract}

\section{Introduction}

In their efforts to promote sustainability local governments around the world are confronting the challenge of mitigation and adaptation to climate change because climate changerelated disturbances can transform the face of communities in profound ways. It is clear that no thorough plan promoting sustainability should ignore the potential impacts of climate change. Sustainability is closely related to the capacity of systems to persist and transform themselves in the presence of significant perturbations and still provide the ecosystem services that sustain life. Holling [1] has defined sustainability as "the capacity to create, test, and maintain adaptive capacity" while Lebel et al. [2] argue that in order to attain sustainable development, societies need to enhance their capacity to manage resilience.

To deal successfully with climate change, decision makers in urban areas have to apply adaptive management, develop the ability to live with uncertainty, and foster transformations without losing opportunities for achieving a sustainable future. Climate change is one of the main sources of uncertainty facing all levels of government today. According to Wilson [3], "building climate change considerations into planning processes and systems allows early action, which should be more cost-effective than responding to changes as they happen or retrospectively." This view is shared by Kirshen et al. [4] when advocating for proactive strategies to cope with climate change in Boston's diverse infrastructure systems.

Urban systems across the entire planet are responding in many different ways to the threats of climate change. The International Council on Local Environmental Initiatives (ICLEI) has fostered some of these efforts through programs such as Cities for Climate Protection (CCP), a commitment that requires the formulation of a Climate Action Plan. With active participation in CCP, cities are stimulated to 
apply adaptive management through an ongoing process of learning, monitoring and assessment of progress, sharing of lessons learned, identifying gaps in knowledge, and facilitating community involvement. However, success in building community resilience to climate change will require cultural transformations as well, since the implementation of adaptive management faces significant barriers born of inertia, and the most difficult of such barriers to overcome are often social rather than technical in character [5]. Through a variety of initiatives ICLEI has been contributing to substantial transformation in urban settings in many areas of the world [6].

Making a commitment to address climate change is the first step toward responsible action; however, taking effective concrete measures reflecting that commitment is the real challenge since many physical, social, and political factors influence the outcome of any sustainability-promoting effort. Changes in planning to increase resilience are not sustainable without cultural changes, because people drive institutions, networks, and the dynamics of social-ecological systems. Issues of social capital, tolerance of unconventional thinking, and diversity are closely related to sustainability and adaptation to climate change. In relation to sustainability, Budd et al. [7] found a direct relationship between social capital and urban sustainability in a group of nearly fifty major US cities. Given these findings it is likely important to understand how some social aspects of a community can contribute to the building of resilience in the face of societal uncertainty.

Building adaptive capacity to undertake the challenges of climate change has become a priority for many urban areas, especially considering the fact that more than half of the world's population lives in urban areas and that percentage is projected to increase $[8,9]$. Fortunately, a strong stream of literature about how to create adaptive capacity and build resilience in natural systems exists [10-17]. However, the key social factors that facilitate the effective building and maintenance of urban resilience remain poorly understood notwithstanding this literature. Given the salience of climate change concerns, there is a pressing need for advancing research on the complexity of urban systems in relation to resilience to climate change. This need has been recognized by the Resilience Alliance (http://www.resalliance.org/) and has led to the launching of an international effort known as the Urban Resilience Project; this project seeks to assess urban systems through the lens of resilience.

With the aim of contributing to the understanding of the social factors that shape adaptive capacity to the uncertain outcomes of climate change in urban areas, two groups of cities with clear differences in sustainability promotion and climate change actions were selected for this study. Selection of cities was based on their performance on climate change issues as reported by ICLEI's CCP reports of milestones accomplished (http://www.iclei.org/). All of the cities in the analysis belong to the group of the 50 largest (by population) cities in the United States. The first group of cities each exhibit good to excellent performance on climate change issues and have each accomplished from three to five (out of five) milestones in the Cities for Climate Protection
Program. In contrast, the second group of cities are either not participating in CCP or have accomplished no more than one of the CCP milestones.

These cities are compared with respect to their actual process of building adaptive capacity and resilience using as an indicator their performance on climate change issues. The climate change performance indicator is used here because proactive behavior to mitigate the impacts of climate change, and especially to adapt and create new sets of conditions in a visionary anticipation of a changing future, will increase the probability of their successful adaptation in the presence of climate change-related events. This close relationship between high performance on climate change issues and the enhancement of urban resilience is also highlighted by Newman et al. [18] when describing their ideal conception of a resilient city.

The cities are also contrasted with respect to several noteworthy social features that are postulated to contribute to adaptive capacity and resilience to climate change. Comparative analysis of these two groups of cities will increase understanding of the social dimensions of resilience to climate change by determining which of the social factors considered in this study can be shown to distinguish climate change resilient from nonresilient urban areas. The analysis set forth here is focused on three core research questions, each of which deals with a distinct aspect of the urban environment. The research questions are focused on each city's performance on climate change issues and their connection to the following social attributes: level of social capital, level of openness to new ideas and unconventional thought, and degree of cultural diversity.

(1) Could social capital explain differences in resilience to climate change between the two groups of cities? Social capital, in particular weak ties or bridging social capital as opposed to bonding social capital among community members, is widely believed to be essential in mobilizing resources and sharing ideas and experiences, especially in this era featured by a multitude of channels of communication and continued progress in the development of digital information technology. Sharing information is vital to enhance resilience, and the presence of social capital facilitates the dissemination of knowledge, not only within the city but also across regions and even countries.

(2) Could differences in resilience to climate change between the two groups of cities be related to people's willingness to consider new ideas? Features such as open-mindedness among the residents of urban areas are key factors that facilitate the emergence of new ideas and innovative projects that give those cities an advantage in dealing successfully with climate change successfully.

(3) Is there a significant difference in cultural diversity that might facilitate the process of building adaptive capacity and resilience to climate change between the two groups of cities? It is widely believed that communities that are open to diversity of people and 
ideas are in a better condition to foster creativity and innovation than communities where social homogeneity predominates.

Our hypothesis is that cities with better performance on climate change issues, which are considered more resilient cities, feature people with a higher level of trust among individuals, a higher level of open-minded thinking, more willingness to embrace new ideas and projects, and higher levels of cultural diversity. The capacity of urban areas to accept change and reorganize themselves is likely somewhat dependent on some of these social features, and reasonable measures for all of these concepts will be needed in our comparison cities to answer the four sets of research questions posed previously.

\section{Resilience and Urban Systems}

Resilience is the ability of a system to absorb disturbances, to recover, and to reorganize while retaining the same structure, functions, and feedbacks after suffering a major perturbation [16]. Gunderson and Holling [19] assert that resilience can be measured by "the magnitude of the disturbance that can be absorbed before the system changes its structure by changing the variables and the processes that control behavior." Carpenter and Brock [20] advocate for focusing attention on three features of resilience: the amount of disturbance that the system can receive without changing its structure and processes, the capacity of the system to self-organize after a disturbance, and the ability to enhance its capacity for learning and adaptation.

In relation to cities, Alberti et al. [21] define urban resilience as "the degree to which cities tolerate alteration before reorganizing around a new set of structures and processes." Urban resilience, they note, is related to the degree to which the city can maintain human functions as well as ecosystem functions.

Paton and Johnston [22] conceptualize resilience in relation to the ability of people and society to adapt to a changing world and to take advantage of the new possibilities offered by change and disturbance. Emphasis on building adaptive capacity through active learning and creative adaptation is posed by Beatley [23]. He maintains that managing resilience is intimately related to the capacity of communities for timely and effective response and recovery when disasters occur; such responses depend heavily on local community institutions and social networks. Following the same line of thought, Buckle [24] argues that resilience might be strengthened by elements such as knowledge of hazards, shared community values, positive social and economic trends, healthy partnerships among social groups and organizations, and strong social communication infrastructures.

What can be said about the ways in which enhancement of urban resilience might be achieved? Four such elements are emphasized by Folke et al. [25] as crucial in building resilience and adaptive capacity: (1) learning to live with disturbances and uncertainty, (2) nurturing diversity for reorganization and renewal, (3) combining different types of knowledge for learning, and (4) creating opportunities for self-organization. Each of these elements can be seen in efforts made at the local level to deal with the uncertainties of climate change impacts. The case of King County, Washington, provides a good example [26]. One of the most advanced local governments on adaptation to climate change in the USA, King County, has received widespread notice for its Climate Action Plan. The plan not only documents challenges but also identifies opportunities to shape change by improving environmental quality, fostering flexibility as new conditions arise, establishing partnerships with academic groups to advance research on climate impacts, involving the public in discussion on climate change issues, communicating its experiences to other local governments, and maintaining mechanisms for ongoing performance evaluation [26].

\section{Urban Resilience to Climate Change Impacts}

The effective undertaking of climate change-related planning actions in response to climatic disturbances depends on the capacity of communities to accept change and reorganize and even take advantage of events to foster adaptive transformations. This capacity to accommodate change should be reflected in concrete actions such as those aimed at decreasing the community's carbon footprint as well as those directed toward preparation for unpredictable disaster events resulting from climate change. It follows that a good way to evaluate the adaptive capacity of urban areas to climate change is to look at concrete climate change anticipatory actions that have been undertaken.

In this respect, strategies in several areas of urban planning might increase resilience to climate change. One of the most important transformations facing urban areas is the reduction of oil dependence through the implementation of renewable energy projects, and most importantly through the planning of cities in a way that allows for reduced dependence on automobiles by providing high-density mixed-use development and climate friendly transportation choices. Resilient cities likely require resilient people; it follows that, improving public health through the fostering of walking and biking almost certainly plays a significant role in the promotion of resilience. These are some of the factors included in the climate change action index created in this study. In this regard, cities with high performance in climate change issues are considered more resilient as compared to those that are not taking action to mitigate or preparing to confront climate change impacts. But what kind of relationship does exist between the city's performance on climate change issues and the social structure of the community? As Longstaff and Yang [27] assert, in trying to understand the ways to increase community resilience the first thing to do is to understand the key features that make people and institutions more resilient. Social features believed to play an important role in building adaptive capacity include social capital, open mindedness, and cultural diversity. These features and their postulated relationship to resilience are briefly explained in Section 4. 


\section{Social Features of Urban Resilience to Climate Change}

4.1. Social Capital. Social capital refers to connections among people through social networks but also includes norms and trust that facilitate a shared community response to common objectives [28]. A number of scholars maintain that social capital is an essential condition to build community resilience to major disturbances $[23,27,29,30]$. In this regard, Tompkins and Adger [31] argue that "present and future vulnerabilities have strong social elements because both are a function of adaptive capacity, which is in turn dependent on social capital, institutions, and resources and their distribution." Adger [32] also argues that the adaptive capacity of communities to deal with climate change is determined by their ability for collective action, which is in turn dependent on trust and social networks. Along the same lines, Newman et al. [18] advocate for the integration of cultural and lifestyle changes as a way of fostering urban resilience; they note that the human capacity some communities have demonstrated in dealing with catastrophes will determine success in the climate change setting as well. Putnam [33] emphasizes that the bridging type of social capital, as opposed to the bonding type, is the model that most likely would contribute to the fulfillment of needs in the broader society.

4.2. Open-Mindedness. The process of building adaptive capacity for dealing with disturbances might be benefited by people's attitude of openness to change and to tolerate different ideas and perspectives because resilience is at least in part about embracing change. For instance, Newman et al. [18] suggest that cities, which are more open to experimentation and innovation, adapt faster than cities that lack these characteristics. An open-minded attitude, especially in dealing with people coming from different backgrounds, is considered to be relevant to building trust and enhancing adaptive capacity [34]. In the same vein, Kofinas et al. [35] agree on the strong link between openness to new ideas and the enhancement of creativity and innovation, which are also key attributes of resilience.

4.3. Diversity. In relation to diversity, extensive research has demonstrated the key role of ecological diversity in building resilience as a source of renewal and reorganization [2]. Sources of renewal and reorganization can also be found in social diversity because diversity is conducive to the emergence of new ideas and solutions. New ideas can also flourish when the incorporation of practical knowledge from local people increases the understanding of environmental problems [36]. In this regard, Lebel et al. [2] assert that the timely identification of thresholds and, in turn, the effective management of resilience both depend on the ability of systems to integrate understanding from different sources. These sources include not only varying forms of scientific understanding but also tacit or practical local knowledge as well.

\section{Methods}

To answer the three research questions posed a series of steps were undertaken. The first step was the selection of the cities of the study. Then, in order to perform statistical analysis to determine to what extent the social features considered in the research discriminate among resilient and nonresilient urban areas, a series of indices were generated. The first such index is the Climate Change Index, which was generated on the basis of cities' performance on climate change issues. Three other indices, each related to social features of the population, include the Open-Mindedness Index, the Social Capital Index, and the Cultural Diversity Index.

The next step involved the statistical analysis of the data assembled using the Statistical Package for the Social Sciences-SPSS Statistics_-version 17. The following is a brief description of each analytical step taken.

5.1. Selection of the Cities. Cities were selected using three criteria. The first criterion was the size of the city. With the purpose of maintaining an acceptable range of city size for comparison purposes, all cities were selected from the group of the 50 largest cities in the USA by population [37]. The second criterion corresponds to the availability of data on social dimensions featured in the Leigh Stowell Archival Dataset-namely, social capital and open-mindedness. Finally, to classify the cities in two distinct groups, namely, climate change active and climate change inactive cities, the dataset of International Council of Local Environmental Initiatives [38] was examined. ICLEI promotes several programs for local governments worldwide, and these programs are focused on helping local governments in their efforts to promote sustainability and address climate change issues. The most influential of these programs is one known as Cities for Climate Protection (CCP), which is the lone program that requires performance evaluation based on five specific documented milestones. Table 1 summarizes the five milestones of the CCP Program.

Cities with three to five out of five CCP milestones accomplished were considered for selection in group 1 or climate change resilient cities in our study. In contrast, cities in the second group, namely, inactive cities with respect to climate change issues, are cities that either are not committed to CCP or are registered in Cities for Climate Protection but have accomplished one or fewer of the five milestones. Selected cities for this study include the following:

(i) top cities: San Francisco (California), Seattle (Washington), Boston (Massachusetts), Minneapolis (Minnesota), Denver (Colorado), San Diego (California), Chicago (Illinois), and Kansas City (Missouri);

(ii) bottom cities: Fort Worth (Texas), Virginia Beach (Virginia), Oklahoma City (Oklahoma), Jacksonville (Florida), Columbus (Ohio), Las Vegas (Nevada), Cleveland (Ohio), and Louisville (Kentucky).

5.2. The Climate Change Index. To determine differences in performance in addressing climate change issues between the two groups of cities, a climate change index was developed 
TABLE 1: The five milestones of Cities for Climate Protection.

\begin{tabular}{ll}
\hline Milestone & Goal \\
\hline Milestone one & $\begin{array}{l}\text { Conduct a baseline greenhouse gas emissions } \\
\text { inventory }\end{array}$ \\
Milestone two & $\begin{array}{l}\text { Adopt an emissions reduction target } \\
\text { Develop and secure formal approval of a local } \\
\text { Milestone three } \\
\text { climate action plan }\end{array}$ \\
Milestone four & $\begin{array}{l}\text { Implement the plan's policies and measures } \\
\text { Monitor progress, report results, and reevaluate } \\
\text { Milestone five }\end{array}$ \\
\hline
\end{tabular}

Source: [38].

TABLE 2: Attributes of the climate action index.

1. Membership in "Cities for Climate Protection"

2. Formulation of a Climate Action Plan

3. Assessment of city's vulnerability to climate change as part of the climate action plan

4. Use of renewable energy

5. Existence within the city of climate-friendly transportation choices

6. Application of green building standards

7. Solid waste reduction/recycling practices

8. Local food initiatives

9. Education and outreach programs, including mechanisms for public involvement

10. Inclusion of adaptation strategies in the Climate Action Plan

which represents a city's performance on mitigation and adaptive capacity to climate change. Ten equally weighted attributes were included in the index (Table 2). Each of these attributes is worth one point in the construction of the index. The city was awarded one point if the attribute was present and awarded zero otherwise. A mean value was calculated for each group of cities. Data were collected mainly from ICLEI Annual Reports, a review of the city's Climate Action Plan, reports from each city's environmental departments, and from the city's official website. Values of the Climate Change Index for each city of the study are included in Tables 4 and 5. It is important to note that the Climate Change Index is dynamic in nature. Values included represent performance of cities as of December 2010.

5.3. The Social Capital Index. Trust as an indicator of the ability for collective action was evaluated with data from the Leigh Stowell dataset, using two relevant questions as shown in Table 3. Response options for each of the questions in the Leigh Stowell dataset range from 1 (disagree strongly) to 5 (agree strongly). The lower value of response options represents the higher value of the attribute. For instance, in the case of trust, strong agreement on the statement denotes lack of social trust in public officials and in people in general, respectively. Mean values of responses to the two trustrelated questions were added together to obtain the Social
Capital Index. Values of the Social Capital Index could in theory range from 2 to 10 as shown in Table 3.

5.4. The Open-Minded Thinking Index. The relationship between cities' resilience to climate change and openness to new ideas was also evaluated using data from the Stowell dataset. Three questions were selected to examine the level of open-minded thinking within the population (Table 3). As was indicated previously, response options range from 1 (disagree strongly) to 5 (agree strongly) with the statement. Likewise, lower scores on the commitment-to-convention items indicate more openness to change. The Open-Minded Thinking Index was generated from the sum of the mean values of responses of these three relevant questions. The Open-Minded Thinking Index could range in theory from 3 to 15 (Table 3 ). The level of unconventional thought was considered relevant since in order to be adaptive, people need to posses or develop the ability to adjust to new sets of opportunities and conditions in the face of uncertainty.

The Stowell dataset was donated to Washington State University by the marketing firm Leigh Stowell \& Company of Seattle. It is composed of data generated through surveys conducted in major media markets in the USA and Canada over the period 1989 to 2005 . The datasets include valuable information on psychographic features such as beliefs, values, and attitudes, which are relevant when analyzing social resilience to climate change. Sample sizes for each city in our study range from about 4,300 to 9,600.

5.5. The Cultural Diversity Index. In order to determine the influence of cultural diversity on resilience to climate change, the Cultural Diversity Index was calculated. The Cultural Diversity Index is based on the Index of Ethnolinguistic Fractionalization [39]. Ottaviano and Peri [40] also applied the model to calculate cultural diversity based on country of birth of the population within a community. The Cultural Diversity Index is based on the probability that two individuals randomly selected from a population belong to different ethnic groups and that probability is expressed as

$$
\text { Cultural Diversity Index }=1-\sum_{i=1}^{N}\left(\frac{\text { Ethnic }_{i}}{\text { Total population }}\right)^{2}
$$

where Ethnic $_{i}$ represents the number of people from an ethnic group within the city and $N$ is the number of ethnic groups represented in the total population of the city. The index ranges theoretically from zero (all individuals belong to the same ethnic group) to 1 (each individual belongs to a different ethnic group). Therefore, the higher the index is, the more culturally diverse is the city.

The Cultural Diversity Index was generated using data on ethnicities derived from the U.S. Census Bureau. Values of the Cultural Diversity Index for the cities of the study are shown in Tables 4 and 5.

5.6. Statistical Analysis. Standardized values of the OpenMinded Thinking Index, the Social Capital Index, and the Cultural Diversity Index were combined for the two groups 
TABLE 3: Sets of questions from the stowell dataset.

\begin{tabular}{|c|c|c|c|}
\hline Social feature & Question from the Leigh Stowell dataset & Range of response options* & Range of values for index* \\
\hline \multirow{2}{*}{$\begin{array}{l}\text { Trust as a measure of } \\
\text { social capital }\end{array}$} & $\begin{array}{l}\text { (1) "Most public officials are only interested in } \\
\text { people with money" }\end{array}$ & $1-5$ & \multirow[t]{2}{*}{$2-10$} \\
\hline & $\begin{array}{l}\text { (2) "Too many people are getting free ride in } \\
\text { today's society" }\end{array}$ & $1-5$ & \\
\hline \multirow{3}{*}{$\begin{array}{l}\text { Open-minded } \\
\text { thinking }\end{array}$} & $\begin{array}{l}\text { (1) "I believe everything is changing too fast } \\
\text { today" }\end{array}$ & $1-5$ & \multirow{3}{*}{$3-15$} \\
\hline & $\begin{array}{l}\text { (2) "I believe the word was created in six days, just } \\
\text { like the Bible says" }\end{array}$ & $1-5$ & \\
\hline & $\begin{array}{l}\text { (3) "I believe all young men should serve in the } \\
\text { military" }\end{array}$ & $1-5$ & \\
\hline
\end{tabular}

Source: Leigh Stowell dataset.

* The lower the value of response, the higher the value of the attribute.

TABLE 4: Features of top cities.

\begin{tabular}{|c|c|c|c|c|c|c|c|c|}
\hline \multirow{2}{*}{ City } & \multirow{2}{*}{ Population } & \multicolumn{5}{|c|}{ Ethnicity (percentage of the total population) } & \multirow{2}{*}{$\begin{array}{l}\text { Cultural } \\
\text { Diversity } \\
\text { Index }\end{array}$} & \multirow{2}{*}{$\begin{array}{c}\text { Climate } \\
\text { Change } \\
\text { Index }\end{array}$} \\
\hline & & White & Black & Asian & Hispanic & $\begin{array}{c}\text { American } \\
\text { Indian and } \\
\text { Alaska Native }\end{array}$ & & \\
\hline San Francisco & 776,733 & 49.7 & 7.8 & 30.8 & 14.1 & 0.5 & 0.632 & 9 \\
\hline Seattle & 563,374 & 70.1 & 8.4 & 13.1 & 5.3 & 1.0 & 0.481 & 10 \\
\hline Boston & 589,141 & 54.5 & 25.3 & 7.5 & 14.4 & 0.4 & 0.613 & 8 \\
\hline Minneapolis & 382,452 & 65.1 & 18 & 6.1 & 7.6 & 2.2 & 0.534 & 8 \\
\hline Denver & 554,636 & 65.3 & 11.1 & 2.8 & 31.7 & 1.3 & 0.460 & 7 \\
\hline San Diego & $1,223,400$ & 60.2 & 7.9 & 13.6 & 25.4 & 0.6 & 0.548 & 7 \\
\hline Chicago & $2,896,016$ & 42 & 36.8 & 4.3 & 26 & 0.4 & 0.619 & 9 \\
\hline Kansas City & 441,545 & 60.7 & 31.2 & 1.9 & 6.9 & 0.5 & 0.529 & 7 \\
\hline
\end{tabular}

Source of data: [37].

of cities, and a statistical analysis was performed using the Independent-Samples $t$-test to determine whether there are significant differences in the mean values of social features for the two groups of cities that might explain differences in adaptive capacity to climate change. Before applying bivariate correlations, all indices were standardized to an ascendant scale, which ranges from zero as the lowest value to 1 as the highest value, for the purpose of facilitating the understanding of the relationships among the different variables included in the study. Finally, the Pearson Product Moment Correlation Coefficient was calculated to examine the link between the social attributes considered in this research and with resilience indicators.

\section{Results}

From data on performance on climate change issues displayed in Tables 4 and 5, the mean value of the Climate Change Index for each group of cities was calculated. The average of Climate Change Index for the top cities is 8 , while for the bottom group it is 3.25. Clearly, there is a great difference between the two groups of cities. As indicated previously, cities with high performance in climate change issues are considered to be more resilient as compared to those that are not taking action to mitigate or confront climate change impacts.

The level of trust as a measure of social capital indicates a statistically significant difference between the mean of the top and bottom cities: on average, the top cities exhibited more trust $(M=0.03, \mathrm{SE}=0.004)$ than the bottom cities $(M=0.23, \mathrm{SE}=0.004)$. This difference was statistically significant $t(103,798)=33.92, P<0.05$. It is important to remark that in the Stowell dataset higher values in responses are associated with lower levels of social capital.

In relation to unconventional thought or open-minded thinking attitude, the top cities exhibited more open-minded thinking attitude $(M=0.04, \mathrm{SE}=0.004)$ than the bottom cities $(M=0.28, \mathrm{SE}=0.005)$. This difference is statistically significant $t(105,698)=40.14, P<0.05$.

The mean values of the two groups of cities also differ in their level of cultural diversity, as measured by the diversity of ethnicities residing within each city. On average, the top cities exhibited more diversity $(M=0.55, \mathrm{SE}=0.02)$ than the bottom cities $(M=0.49, \mathrm{SE}=0.01), t(14)=2.30 P<0.05$.

The Pearson Product Moment Correlation Coefficient was calculated to examine the relationship among attributes. The Climate Change Index was significantly correlated to the Social Capital Index, The Open-Minded Thinking Index, and 
TABLE 5: Features of bottom cities.

\begin{tabular}{|c|c|c|c|c|c|c|c|c|}
\hline \multirow{2}{*}{ City } & \multirow{2}{*}{ Population } & \multicolumn{5}{|c|}{ Ethnicity (percentage of the total population) } & \multirow{2}{*}{$\begin{array}{c}\text { Cultural } \\
\text { Diversity } \\
\text { Index }\end{array}$} & \multirow{2}{*}{$\begin{array}{c}\text { Climate } \\
\text { Change } \\
\text { Index }\end{array}$} \\
\hline & & White & Black & Asian & Hispanic & $\begin{array}{c}\text { American } \\
\text { Indian and } \\
\text { Alaska Native }\end{array}$ & & \\
\hline Fort Worth & 535,420 & 59.7 & 20.3 & 2.6 & 29.8 & 0.6 & 0.513 & 1 \\
\hline Virginia Beach & 425,257 & 71.4 & 19 & 4.9 & 4.2 & 0.4 & 0.450 & 2 \\
\hline Oklahoma City & 505,963 & 68.4 & 15.4 & 3.5 & 10.1 & 3.5 & 0.496 & 2 \\
\hline Jacksonville & 735,617 & 64.5 & 29 & 2.8 & 4.2 & 0.3 & 0.497 & 2 \\
\hline Columbus & 711,470 & 67.9 & 24.5 & 3.4 & 2.5 & 0.3 & 0.477 & 3 \\
\hline Las Vegas & 478,434 & 69.9 & 10.4 & 4.8 & 23.6 & 0.4 & 0.443 & 5 \\
\hline Cleveland & 478,403 & 41.5 & 51.0 & 1.3 & 7.3 & 0.3 & 0.562 & 5 \\
\hline Louisville & 554,496 & 62.9 & 33 & 1.4 & 1.9 & 0.2 & 0.495 & 5 \\
\hline
\end{tabular}

Source of data: [37].

TABLE 6: Bivariate correlation coefficients.

\begin{tabular}{|c|c|c|c|c|}
\hline & $\begin{array}{c}\text { Climate } \\
\text { Change } \\
\text { Index }\end{array}$ & $\begin{array}{c}\text { Social } \\
\text { Capital } \\
\text { Index }\end{array}$ & $\begin{array}{c}\text { Open- } \\
\text { Minded } \\
\text { Thinking } \\
\text { Index }\end{array}$ & $\begin{array}{c}\text { Cultural } \\
\text { Diversity } \\
\text { Index }\end{array}$ \\
\hline $\begin{array}{l}\text { Climate Change } \\
\text { Index }\end{array}$ & 1 & & & \\
\hline $\begin{array}{l}\text { Social Capital } \\
\text { Index }\end{array}$ & $0.763^{* *}$ & 1 & & \\
\hline $\begin{array}{l}\text { Open-Minded } \\
\text { Thinking Index }\end{array}$ & $0.654^{* *}$ & $0.572^{*}$ & 1 & \\
\hline $\begin{array}{l}\text { Cultural Diversity } \\
\text { Index }\end{array}$ & $0.498^{*}$ & 0.359 & $0.665^{* *}$ & 1 \\
\hline
\end{tabular}

** Correlation is significant at the 0.01 level.

${ }^{*}$ Correlation is significant at the 0.05 level.

the Cultural Diversity Index as shown in Table 6. To illustrate the strong and positive relationship between the Climate Change Index as an indicator of urban resilience to climate change and the social features of the population considered in this study, Figures 1, 2, and 3 are included. The scale of the horizontal axis was adjusted to the actual range of values in these three figures in order to show the relative position of each city.

The difference in resilience to climate change between the two groups of cities is accompanied by a statistically significant difference in trust as a measure of social capital. The level of trust within the cities is strongly correlated with the Climate Change Index (correlation coefficient of 0.763 , significant at the 0.01 level). The degree of social capital is postulated to be an important factor in building social resilience to climate change, as supported by the fact that more resilient cities exhibited higher levels of trust. Figure 1 illustrates the relative position of each of the cities of the study with respect to trust as a measure of social capital.

There is also a significant difference in people's willingness to consider new ideas between the two groups of cities. This result is supported by the fact that the Climate Change

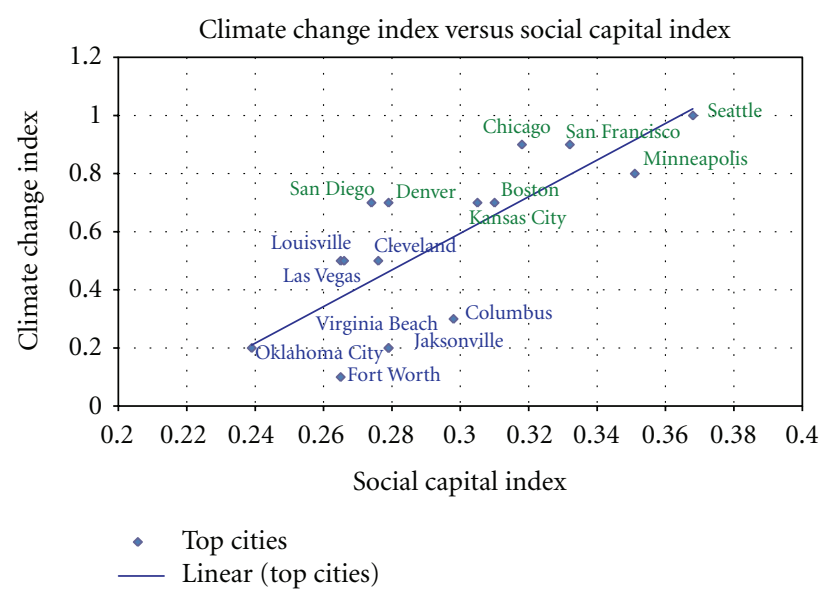

FIGURE 1: Relationship between climate change action and social capital.

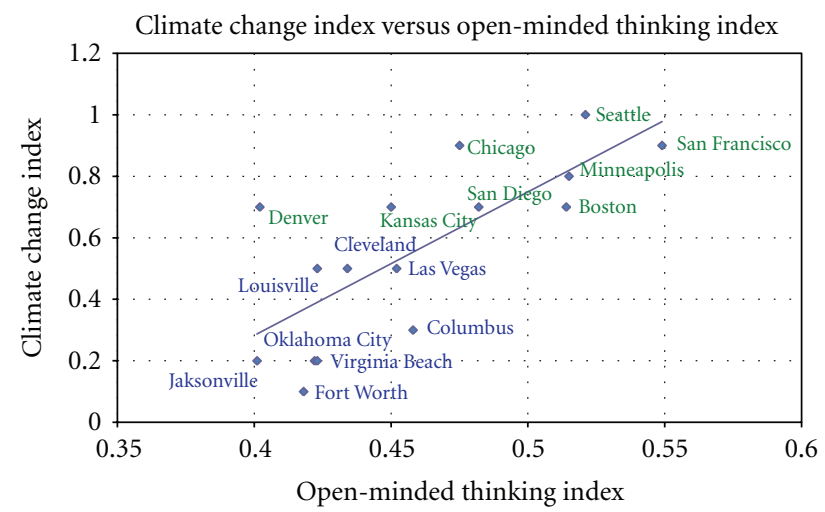

FIGURE 2: Relationship between climate change action and openmindedness.

Index is strongly and significantly correlated with openminded thinking disposition (correlation coefficient of 0.654 significant at the 0.01 level). Figure 2 illustrates the position of each of the cities of the study in regards to openmindedness attitude. 


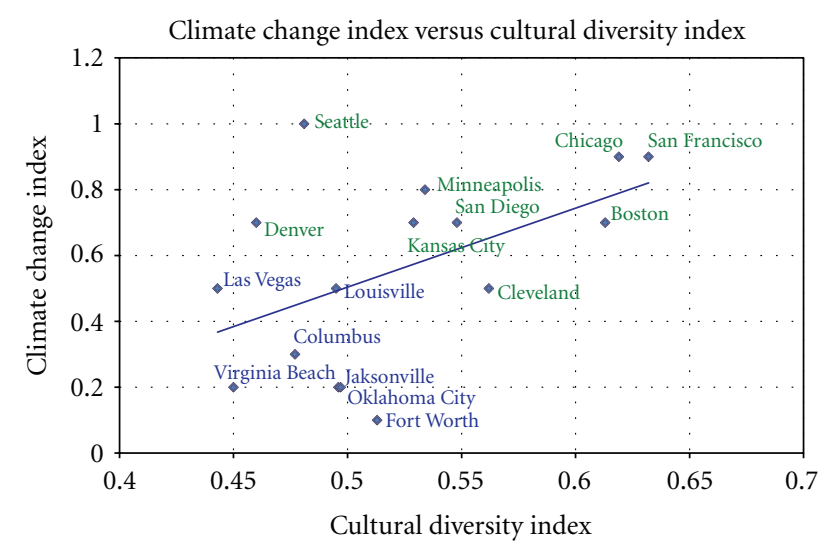

FIGURE 3: Relationship between climate change action and cultural diversity.

Likewise, there is a significant positive link between the level of cultural diversity within the cities of the study and their commitment to climate change issues as a measure of adaptive capacity. The correlation coefficient between the Cultural Diversity Index and the Climate Change Index was 0.498 , significant at the 0.05 level. Figure 3 illustrates the situation of the cities of the study in relation to the cultural diversity of the population.

\section{Discussion}

The two groups of cities exhibit a clear difference in performance on climate change issues and, we argue, on building adaptive capacity to confront potential impacts of climate change. The results support our hypothesis that more resilient urban areas exhibit a greater level of social capital, a higher degree open-minded thinking attitude, and a more culturally diverse population.

More resilient cities in this study showed higher levels of trust among the members of the communities. Social capital in the form of weak ties-the bridging type of social capital-is believed to be an essential element in mobilizing resources and communicating and sharing experiences in the face of major disturbances to urban areas. It is important to note that there are two types of social capital: bonding and bridging. The bridging type appears to be more important for building adaptive capacity and resilience while the bonding type might in some cases decrease opportunities for innovation and flow of information that are crucial for resilience. The social capital index shown in this research does not separate the bridging from the bonding type. Future research in this direction might focus on the relationship of each of these types of social capital and the process of building adaptive capacity to confront climate change impacts.

More resilient cities are also proactive and innovative in finding solutions to guide the city to a more sustainable and adaptive path as compared to less resilient cities. We argue that their performance on one of the most pressing issues for urban planning, which is climate change, gives them an

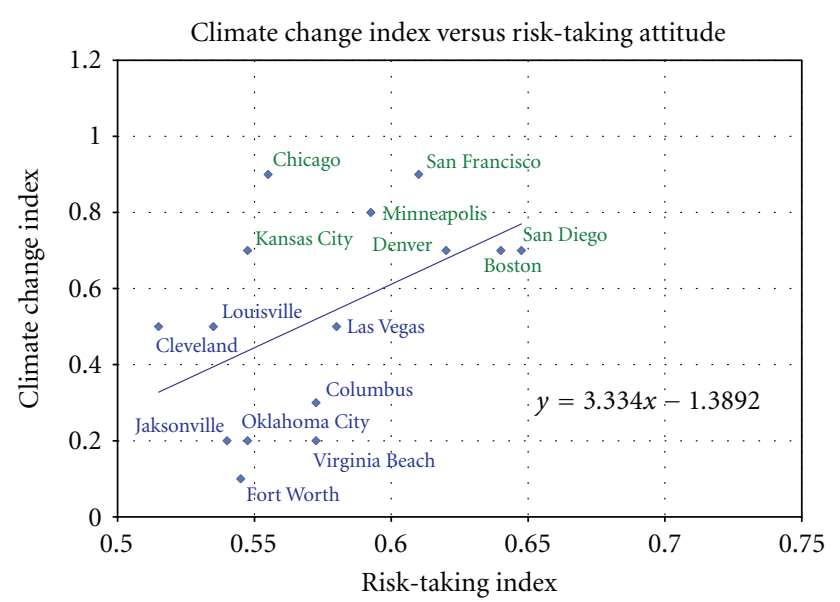

FIGURE 4: Relationship between climate change action and risk taking attitude.

advantage in confronting the uncertainty of climate-related perturbations.

Likewise, diversity is an asset in confronting the challenges of climate change. Cultural diversity also maintains a strong and significant relationship with the Climate Change Index, as shown in Table 6 and Figure 3. It is widely recognized that diversity plays a crucial role in building resilience in social ecological systems. Results of this research lend support for this theory, as more resilient cities exhibited higher levels of cultural diversity as measured by the presence of different ethnic groups. Higher levels of cultural diversity can enhance resilience because the novel combination of ideas emerging from people with different backgrounds and perspectives might be conductive to more innovation and creativity, which are key elements in creating a more diverse and rich set of options and solutions to succeed in a world of ongoing transformations.

7.1. Where Might the Risk Takers Be? Closely linked to the attitude of openness to change and willingness to embrace new ideas is a risk-taking disposition. From the outset, this feature was considered relevant to the study of social dimensions of resilience to climate change. A risk-taking mindset among the dwellers of urban areas facilitates the emergence of innovative ideas and projects to tackle current and potential future problems in relation to climate change impacts. The Leigh Stowell dataset contains one question designed to identify the risk takers: "As a rule, I do not believe in taking risks." Unfortunately, data on this question is lacking for the city of Seattle, which, jointly with King County, is part of the central focus of this research. However, an analysis of the remaining 15 cities was conducted to investigate the link between risk taking attitude and resilience to climate change impacts among urban residents. From the findings set forth in Figure 4 it is apparent that the pattern found in social capital, open-minded thinking, and diversity in relation to climate change action is also maintained for a risk-taking way of thinking. There is a strong, linear significant relationship between risk-taking attitude and the Climate Change Index 
(correlation coefficient of 0.490 , significant at 0.05 level). This means that risk takers are thriving in the climate change proactive cities of the study, with San Diego and Boston standing out as leaders in this regard.

Utilizing the equation of the regression line the probable score of Seattle in relation to risk taking attitude was estimated as 0.71 . This value indicates that Seattle might stand higher than the rest of the cities in relation to people's willingness to take risks to embrace new ideas and projects. These results suggest that risk-taking disposition is higher in urban areas with higher behavioral tendency toward building adaptive capacity to climate change.

\section{Conclusions}

Major disruptions of the dynamics of urban systems could well result from the impact of climate change, and success in dealing with these disturbances depends on the capacity of communities to foster transformations. This capacity should be reflected in concrete actions such as those aimed at decreasing the community's carbon footprint and those intended at developing the capacity to withstand undesirable consequences resulting from global climate change. Similarly, the capacity of urban areas to accommodate new conditions is likely dependent on some of their social features; in this regard, openness to change, cultural diversity, and the ability of urban settlers to adapt and to share information and resources in collective action stand out as key elements of resilience.

Our analysis of two groups of cities has supported that position, with evidence that cities exhibiting a higher level of adaptive capacity to confront climate change issues tend to feature populations which exhibit a higher level of openness to new ideas, feature higher level of social capital, and feature greater cultural diversity as compared to cities that are currently less active on climate change issues. It is widely recognized that diversity plays a key role in building resilience. In our study, more resilient cities showed higher levels of cultural diversity as measured by the presence and percentage of different ethnic groups. Higher levels of diversity can enhance resilience because the novel combination of ideas might be conductive to more innovation and creativity, which are essential in creating a more diverse and rich set of options and solutions to face a world of transformations.

However, even though a strong and significant correlation among the social factors postulated to build urban resilience has been demonstrated in this study, much more work is needed to enhance our understanding of urban environments through the resilience perspective. The social dynamics of urban areas is so complex that the current knowledge of the implications of social/cultural aspects of the cities on such an important issue as building adaptive capacity to climate change needs additional study. Besides social capital, unconventional attitude, and cultural diversity, other relevant aspects include the multifaceted issues of social equity.

Some limitations of this study include its focus on a small number of cities and on large metropolitan areas alone. Advancing research in the pressing issue of urban resilience to climate change will require a study of a more representative set of cities, and not only within the United States but also around the world. Similarly, analysis of small and midsize cities, along with large metropolitan areas, will surely provide significant insight.

\section{References}

[1] C. S. Holling, "Understanding the complexity of economic, ecological, and social systems," Ecosystems, vol. 4, no. 5, pp. 390-405, 2001.

[2] L. Lebel, J. M. Anderies, B. Campbell et al., "Governance and the capacity to manage resilience in regional social-ecological systems," Ecology and Society, vol. 11, no. 1, article no. 19, 2006.

[3] E. Wilson, "Adapting to climate change at the local level: the spatial planning response," Local Environment, vol. 11, no. 6, pp. 609-625, 2006.

[4] P. Kirshen, M. Ruth, and W. Anderson, "Interdependencies of urban climate change impacts and adaptation strategies: a case study of metropolitan boston usa," Climatic Change, vol. 86, no. 1-2, pp. 105-122, 2008.

[5] G. Peterson, G.A. DeLeo, J. J. Hellman et al., "Uncertainty, climate change, and adaptive management," Conservation Ecology, vol. 1, no. 2, article 4, 1997.

[6] Y. Strengers, "Environmental culture change in local government: a practised perspective from the international council for local environmental initiatives-Australia/New Zealand," Local Environment, vol. 9, no. 6, pp. 621-628, 2004.

[7] W. Budd, N. Lovrich, J. C. Pierce, and B. Chamberlain, "Cultural sources of variations in us urban sustainability attributes," Cities, vol. 25, no. 5, pp. 257-267, 2008.

[8] Millennium Ecosystem Assessment, Ecosystems and Human Well-Being: Synthesis, Island Press, Washington, DC, USA, 2005.

[9] N. Prasad, F. Ranghieri, F. Shah, Z. Trihanis, E. Kessler, and R. Sinha, Climate Resilient Cities: A Primer on Reducing Vulnerabilities to Disasters, The World Bank, Washington, DC, USA, 2009.

[10] C. Folke, C. S. Holling, and C. Perrings, "Biological diversity, ecosystems, and the human scale," in Foundations of Ecological Resilience, L. Gunderson, C. Allen, and C. S. Holling, Eds., pp. 152-165, Island Press, Washington, DC, USA, 2010.

[11] C. Folke, S. Carpenter, B. Walker et al., "Regime shifts, resilience, and biodiversity in ecosystem management," Annual Review of Ecology, Evolution, and Systematics, vol. 35, pp. 557$581,2004$.

[12] L. Gunderson, "Adaptive dancing: interactions between social resilience and ecological crises," in Navigating Social-Ecological Systems: Building Resilience for Complexity and Change, F. Berkes, J. Colding, and C. Folke, Eds., pp. 33-52, Cambridge University Press, Cambridge, UK, 2003.

[13] C. S. Holling, "Engineering resilience versus ecological resilience," in Foundations of Ecological Resilience, L. Gunderson, C. Allen, and C. S. Holling, Eds., pp. 51-66, Island Press, Washington, DC, USA, 2010.

[14] J. Norberg, J. Wilson, B. Walker, and E. Ostrom, "Diversity and resilience of social-ecological systems," in Complexity Theory for a Sustainable Future, J. Norbeg and G. Cumming, Eds., pp. 46-80, Columbia University Press, New York, NY, USA, 2008.

[15] G. Peterson, C. R. Allen, and C. S. Holling, "Ecological resilience, biodiversity, and scale," in Foundations of Ecological Resilience, L. Gunderson, C. Allen, and C. S. Holling, Eds., pp. 167-193, Island Press, Washington, DC, USA, 2010. 
[16] B. Walker and D. Salt, Resilience Thinking: Sustaining Ecosystems and People in a Changing World, Island Press, Washington, DC, USA, 2006.

[17] B. Walker and N. Abel, "Resilient rangelands-adaptation in complex systems," in Panarchy: Understanding Transformations in Human and Natural Systems, L. Gunderson and C. S. Holling, Eds., pp. 293-313, Island Press, Washington, DC, USA, 2002.

[18] P. Newman, T. Beatley, and H. Boyer, Resilient Cities: Responding to Peak Oil and Climate Change, Island Press, Washington, DC, USA, 2009.

[19] L. Gunderson and C. S. Holling, Panarchy: Understanding Transformations in Human and Natural Systems, Island Press, Washington, DC, USA, 2002.

[20] S. R. Carpenter and W. A. Brock, "Adaptive capacity and traps," Ecology and Society, vol. 13, no. 2, article no. 40, 2008.

[21] M. Alberti, J. M. Marzluff, E. Shulenberger, G. Bradley, C. Ryan, and C. Zumbrunnen, "Integrating humans into ecology: opportunities and challenges for studying urban ecosystems," Bioscience, vol. 53, no. 12, pp. 1169-1179, 2003.

[22] D. Paton and D. Johnston, Disaster Resilience: An Integrated Approach, Charles C. Thomas Publisher, Springfield, Ill, USA, 2006.

[23] T. Beatley, Planning for Coastal Resilience: Best Practices for Calamitous Times, Island Press, Washington, DC, USA, 2009.

[24] P. Buckle, "Assessing social resilience," in Disaster Resilience: An Integrated Approach, D. Paton and D. M. Johnston, Eds., pp. 88-103, Charles C. Thomas Publisher, Springfield, Ill, USA, 2006.

[25] C. Folke, J. Colding, and B. Fikret, "Synthesis: building resilience and adaptive capacity in social-ecological systems," in Navigating Social-Ecological Systems, F. Berkes, J. Colding, and C. Folke, Eds., pp. 352-387, Cambridge University Press, Cambridge, UK, 2003.

[26] C. Saavedra and W. W. Budd, "Climate change and environmental planning: working to build community resilience and adaptive capacity in washington state, usa," Habitat International, vol. 33, no. 3, pp. 246-252, 2009.

[27] P. H. Longstaff and S. U. Yang, "Communication management and trust: their role in building resilience to "surprises" such as natural disasters, pandemic flu, and terrorism," Ecology and Society, vol. 13, no. 1, article no. 3, 2008.

[28] R. D. Putnam, "Tuning in, tuning out: the strange disappearance of social capital in America," Political Science and Politics, vol. 28, no. 4, pp. 664-683, 1995.

[29] W. N. Adger, "Social capital, collective action, and adaptation to climate change," Economic Geography, vol. 79, no. 4, pp. 387-404, 2003.

[30] M. Pelling and C. High, "Understanding adaptation: what can social capital offer assessments of adaptive capacity?" Global Environmental Change, vol. 15, no. 4, pp. 308-319, 2005.

[31] E. L. Tompkins and W. N. Adger, "Does adaptive management of natural resources enhance resilience to climate change?" Ecology and Society, vol. 9, no. 2, article no. 10, 2004.

[32] W. N. Adger, "Social capital and climate change," Tyndall Centre for Climate Research Working Paper 8., University of East Anglia, UK, 2001, http://www.tyndall.ac.uk/content/. social-capital-and-climate-change.

[33] R. D. Putnam, Bowling Alone: The Collapse and Revival of American Community, Simon \& Schuster, New York, NY, USA, 2000.

[34] F. Berkes, "Adaptive co-management and complexity: exploring the many faces of co-management," in Adaptive
Co-Management: Collaboration, Learning, and Multi-Level Governance, D. Armitage, F. Berkes, and N. Doubleday, Eds., pp. 19-37, University of British Columbia Press, Vancouver, Canada, 2007.

[35] G. P. Kofinas, S. J. Herman, and C. Meek, "Novel problems require novel solutions: Innovation as an outcome of adaptive co-management," in Adaptive Co-Management: Collaboration, Learning and Multi-Level Governance, D. Armitage, F. Berkes, and N. Doubleday, Eds., pp. 249-267, University of British Columbia Press, Vancouver, Canada, 2007.

[36] M. Gadgil, P. Olsson, F. Berkes, and C. Folke, "Exploring the role of local ecological knowledge in ecosystem management: three case studies," in Navigating Social-Ecological Systems, F. Berkes, J. Colding, and C. Folke, Eds., pp. 189-209, Cambridge University Press, Cambridge, UK, 2003.

[37] U.S. Census Bureau, "State and county quickfacts," 2000, http://www.census.gov/.

[38] International Council on Local Environmental Initiatives (ICLEI), "Measuring up: a detailed look at the impressive goals and climate action progress of US cities and counties. Progress and potential in 2009," http://www.icleiusa.org/.

[39] P. Mauro, "Corruption and growth," The Quarterly Journal of Economics, vol. 110, no. 3, pp. 681-712, 1995.

[40] G. I. P. Ottaviano and G. Peri, "The economic value of cultural diversity: evidence from US cities," Journal of Economic Geography, vol. 6, no. 1, pp. 9-44, 2006. 


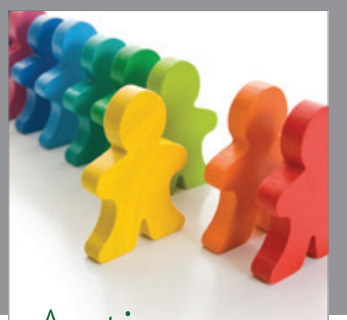

Autism

Research and Treatment
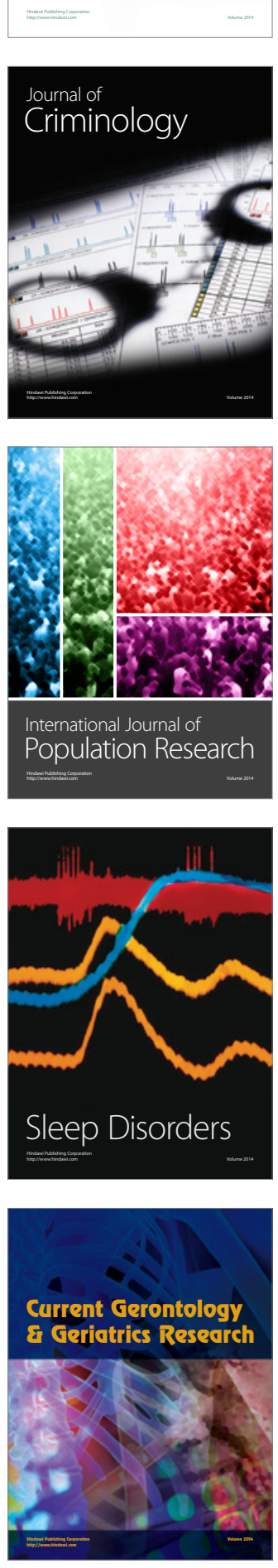
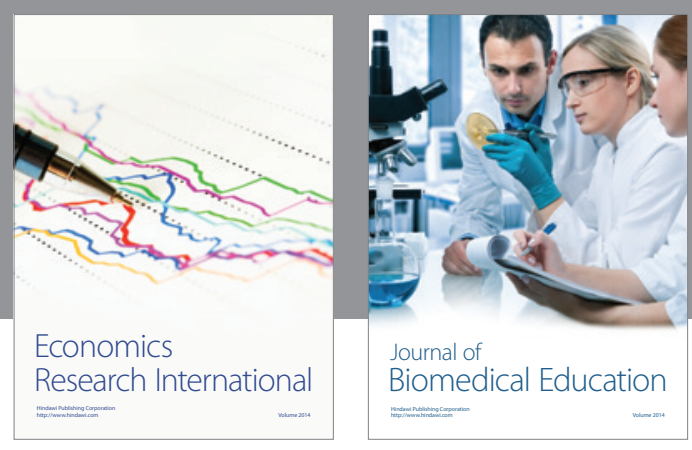

Journal of

Biomedical Education

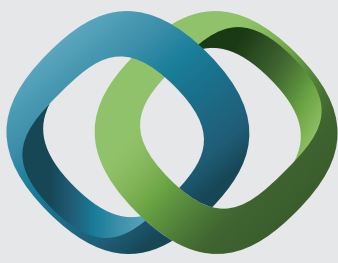

\section{Hindawi}

Submit your manuscripts at

http://www.hindawi.com
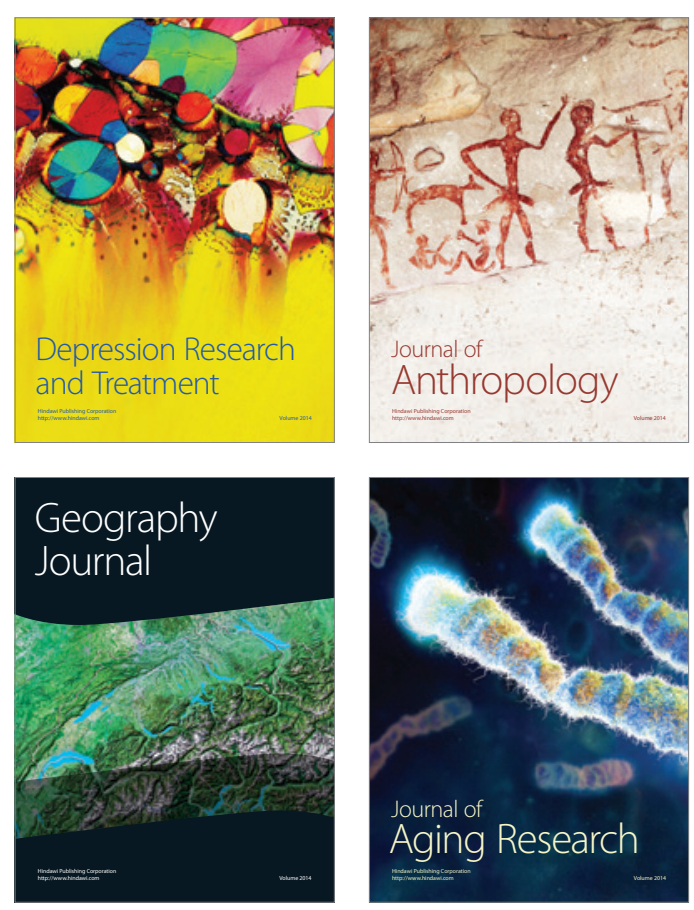

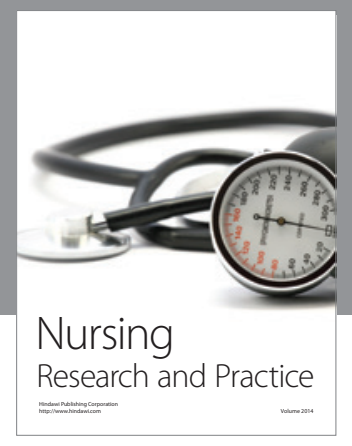

Nursing

Research and Practice

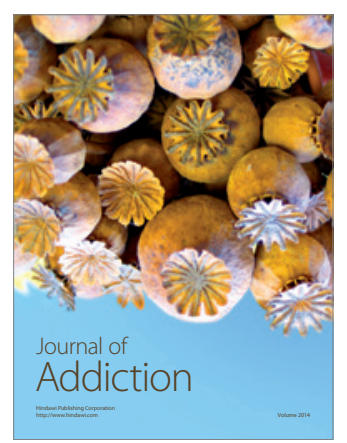

Child Development

Research

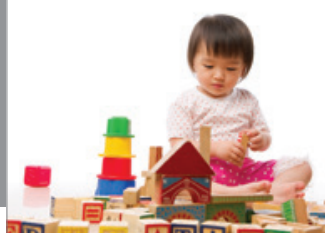

迥
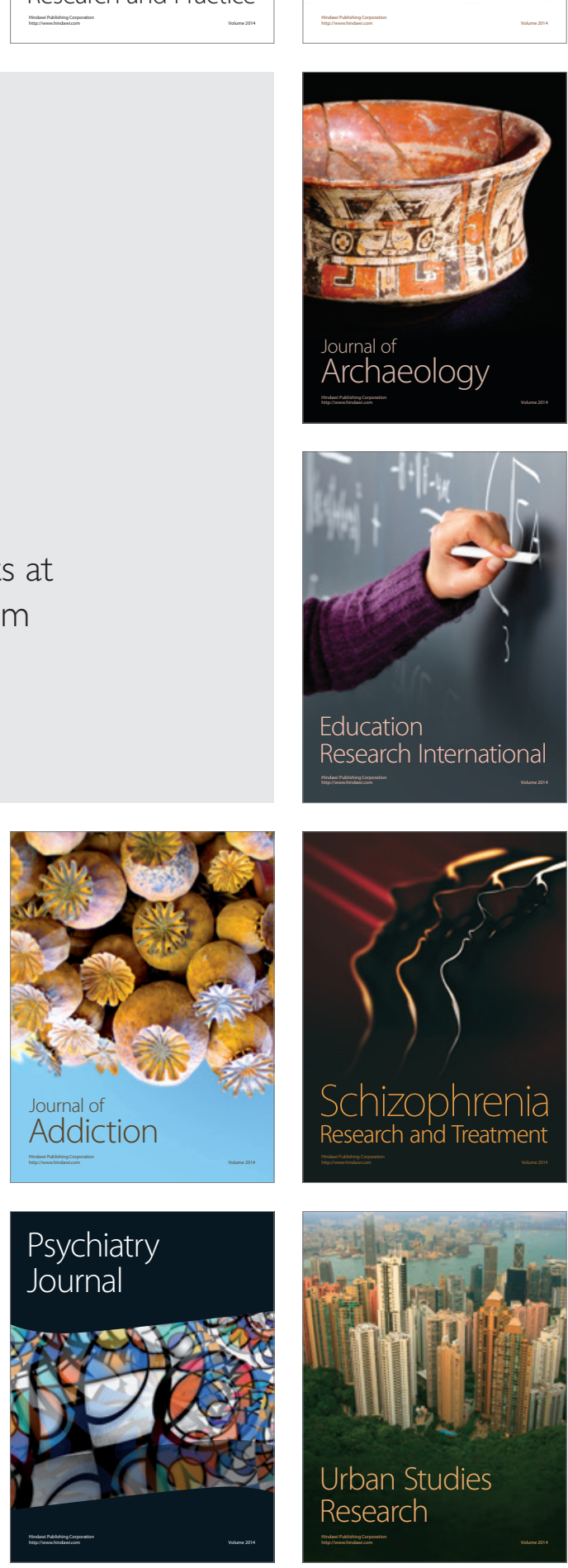